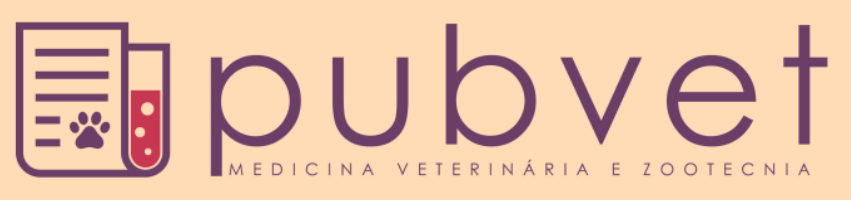

HTTP://DX.DOI.ORG/10.22256/PUBVET.V11N11.1104-1107

\title{
Achado citopatológico de formas amastigota de Leishmania spp. na língua de um canino: Relato de caso
}

\author{
Carolina Pereira Marinho', Isabela Marafon Souza², Marcos Eufrasio Bonato Xavier², \\ Camilla Jaime Dourisboure ${ }^{2}$, Paulo Henrique Braz ${ }^{3 *}$
}

${ }^{1}$ Médica Veterinária Residente em Clínica Médica e Cirúrgica de Pequenos Animais no Centro Universitário da Grande Dourados - UNIGRAN. Dourados - MS Brasil.E-mail: carolmarinho207@gmail.com

${ }^{2}$ Discente do Curso de Medicina Veterinária do Centro Universitário da Grande Dourados - UNIGRAN. Dourados - MS Brasil.E-mail: isasouza28@gmail.com

*Docente do Curso de Medicina Veterinária do Centro Universitário da Grande Dourados - UNIGRAN. Dourados - MS Brasil.E-mail:pauloh.braz@hotmail.com

RESUMO. O objetivo deste trabalho foi relatar um caso de um cão naturalmente infectados por Leishmania spp. com apresentação clínica incomum e não relatada. O canino, sem raça definida, macho, de 4 anos de idade, foi atendido com histórico de ulceração no terço médio da língua, medindo em torno de $2 \mathrm{~cm}$ de diâmetro, com aparecimento há 5 meses. O exame citopatológico foi determinante para a visualização de formas amastigota de Leishmania spp, sendo possível o diagnóstico de leishmaniose.

Palavras chave: Leishmaniose, úlcera, citopatologia, nódulo

\section{Cytopathological finding of amastigote forms of Leishmania spp. in the tongue of a canine: Case report}

\begin{abstract}
The objective of this work was to report a case of a dog naturally infected by Leishmania spp. Unclassified and unreported clinical behavior. The 4-year-old male, without a defined breed, was treated with a history of ulceration without a middle third of the tongue, measuring around $2 \mathrm{~cm}$ in diameter, with appearance 5 months ago. The cytopathological examination was determined for a vision of amastigote forms of Leishmania spp, being possible the diagnosis of leishmaniasis.
\end{abstract}

Keywords: Leishmaniasis, ulcer, cytopathology, nodule.

\section{Hallazgo citopatológico de formas amastigotes de Leishmania spp. En la lengua de un canino: Reporte de un caso}

RESUMEN. El objetivo de este trabajo fue relatar un caso de un perro naturalmente infectado por Leishmania spp. Con una presentación clínica inusual y no reportada. El canino, sin raza definida, macho, de 4 años de edad, fue atendido con histórico de ulceración en el tercio medio de la lengua, midiendo alrededor de $2 \mathrm{~cm}$ de diámetro, con aparición hace 5 meses. El examen citopatológico fue determinante para la visualización de formas amastigotes de Leishmania spp, siendo posible el diagnóstico de leishmaniasis.

Palabras clave: Leishmaniasis, úlcera, citopatología, nódulo

\section{Introdução}

A leishmaniose é uma doença infectoparasitária que acomete animais e seres humanos.
É causada por protozoários do gênero Leishmania, parasitas intracelulares obrigatórios. O meio de transmissão ocorre pela flebotomíneo pertencente 
ao gênero Lutzomyia infectado pelo protozoário que, ao picar o hospedeiro, transmite a doença (Bastos et al., 2012). A partir da infecção com formas promastigotas, o organismo inicia um processo de defesa. Essa defesa se inicia ainda no local da picada, ocorrendo um processo inflamatório. Estabelecido o processo inflamatório, os parasitas irão atingir outros órgãos, como baço, linfonodos e medula óssea, o que irá gerar a resposta imunológica do hospedeiro (Greene et al., 1993).

A apresentação da doença é variada, podendo ser assintomática, oligossintomática ou sintomática. Os pacientes são considerados assintomáticos quando possuem menos de três sintomas referentes à leishmaniose. Os oligossintomáticos possuem de três a cinco sintomas, enquanto que os animais sintomáticos são considerados aqueles que possuem mais de cinco sintomas compatíveis com a doença (Godoy et al., 2017).

O presente relato de caso tem como objetivo demonstrar um cão, diagnosticado com leishmaniose devido ao aparecimento de uma úlcera nodular na língua do animal, forma considerada não canônica.

\section{Material e Métodos}

Um canino, sem raça definida de quatro anos de idade foi atendido na Clínica Veterinária do Centro Universitário da Grande Dourados, apresentando uma lesão ulcerada e circular em terço médio da língua sua língua, medindo aproximadamente 2 centímetros de diâmetro (Figura 1), com aparecimento há cerca de 5 meses. $\mathrm{O}$ tutor do animal relatou que o mesmo se mantinha ativo, com normorexia e clinicamente saudável. Já havia levado a outros locais e efetuado o tratamento para a ulceração.

Foi solicitado exame hematológico, ureia, creatinina, alanina aminotransferase e fosfatase alcalina para monitorização da condição de saúde do animal, além do exame citopatológico da lesão, por punção aspirativa por agulha fina, para diferenciar processos infecciosos de neoplásicos.

$\mathrm{O}$ hemograma revelou discreta trombocitopenia e os exames bioquímicos se mantiveram dentro dos limites da normalidade. $\mathrm{O}$ exame de citopatologia da língua revelou grande quantidade de plasmócitos, células intensamente ativadas (Mott), presença de anisocitose plasmocitária, além de macrófagos fagocitando formas amastigotas de Leishmania spp (Figura 2), concluindo o diagnóstico de leishmaniose.

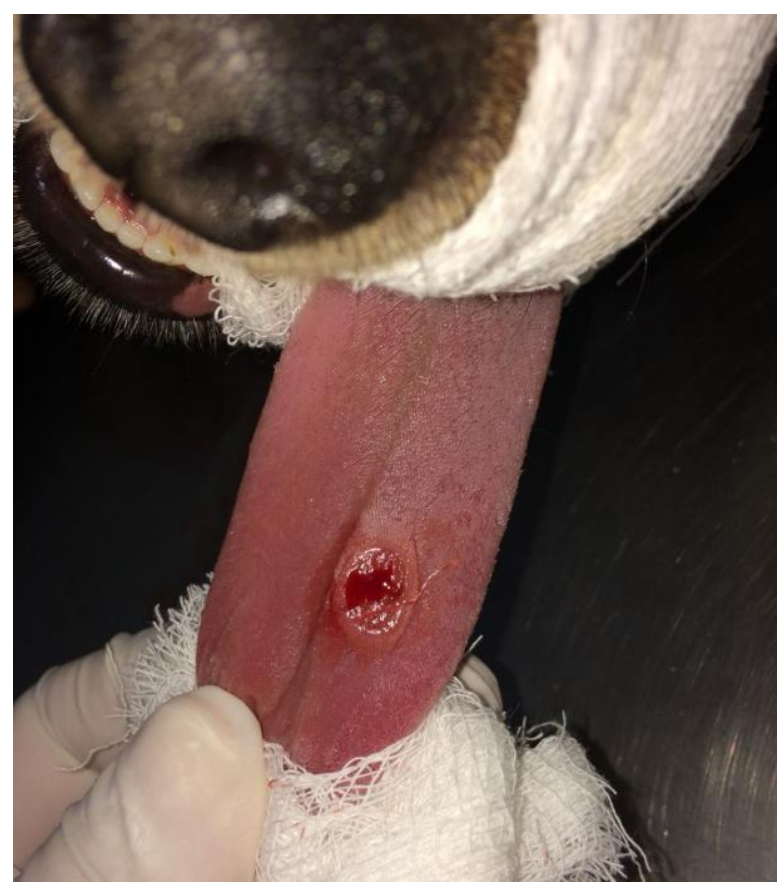

Figura 1. Nódulo em início de terço médio da língua de um canino, com apresentação ulcerativa e sanguinolenta. Base nodular circunscrita de consistência variando de friável a firme

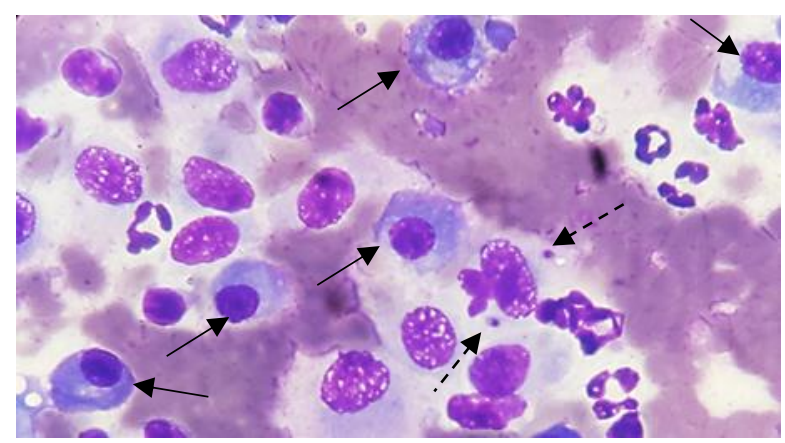

Figura 2. Lâmina citopatológica do terço medial da língua. Setas pontilhadas demonstram macrófagos fagocitando e formas amastigotas de Leishmania spp. Setas pontilhadas demonstram grande quantidade de plasmócitos.

\section{Resultado e Discussão}

A leishmaniose é caracterizada por sinais clínicos muito inespecíficos; porém, por ter preferência por macrófagos, o parasita se concentra em órgãos que tenha maior quantidade destas células, tais como baço, fígado e medula óssea. Quando depositado na medula óssea, a infecção vai gerar uma hipoplasia medular com consequente anemia, trombocitopenia e leucopenia periféricas (Moreira, 2012).

Embora algumas alterações hematológicas em cães com leishmaniose sejam bem descritas, como a presença de discreta anemia normocítica e 
normocrômica, causada, não só pela hipoplasia medular, mas também por sequestro esplênico, eritrólise e hemorragias pela trombocitopenia (Braz et al., 2015), o animal atendido não possuía nenhuma alteração compatível para sugerir a suspeita da doença.

Dentre as principais alterações clínicas encontradas destacam-se as lesões dermatológicas, presente entre 50 a $90 \%$ dos animais (Salzo, 2008). Um dos principais motivos pelo aparecimento destas lesões cutâneas se dá pela multiplicação do parasito acontecer em macrófagos, como os histiócitos (Teixeira et al., 2013).

Formas não canônicas da doença já foram descritas, como presença de formas amastigota em mucosa conjuntival (Lima et al., 2014), líquido sinovial (Silva, 2007), sistema reprodutor (Benites et al., 2011) e miocárdio (Godoy et al., 2016) de cães. Entretanto, o encontro do parasito nestes locais se deve principalmente por haver continuidade da infecção em outras células, ocorrendo o surgimento do parasito em outros locais da pele ou mucosas (Gontijo and Carvalho, 2003, FNS, 2010).

Quando ocorre a picada do flebotomíneo ocorre uma reação inflamatória, gerada pelo sistema imune contra as formas promastigotas de Leishmania spp, desta forma pode ser sugerido que o aparecimento da lesão tenha sido por parasitismo direto, em que o flebotomíneo fez repasto sanguíneo na língua do animal, gerando lesão (Greene et al., 1993).

É importante destacar que o aparecimento da lesão nodular em língua é uma forma pouco frequente de ser encontrada na rotina médicaveterinária. Desta forma, é fundamental que se tenha o diagnóstico diferencial citopatológico para determinar se a causa da lesão é de origem inflamatória, neoplásica ou infecto-parasitária (Braz et al., 2016).

\section{Conclusões}

A leishmaniose é uma doença que gera diferentes manifestações clínicas em cães. Desta forma, em regiões geográficas em que a doença é considerada endêmica, processos nodulares e ulcerosos devem sempre ser avaliados de forma minuciosa para a pesquisa de formas amastigota de Leishmania spp nos materiais colhidos por punção aspirativa.

\section{Referências Bibliográficas}

Bastos, M. M., Boechat, N., Gomes, A. T. P. C'., Neves, M. G. P. M. S. \& Cavaleiro, J. A. S. 2012. O Uso de porfirinas em terapia fotodinâmica no tratamento da Leishmaniose cutânea. Revista Virtual de Química, 4, 257 267.

Benites, A. P., Fernandes, C. E., Brum, K. B. \& Abdo, M. A. G. S. 2011. Presença de formas amastigotas de Leishmania chagasi e perfil leucocitário no aparelho reprodutivo de cães. Pesquisa Veterinária Brasileira, 31, 72-77.

Braz, P. H., Brum, K. B., Souza, A. I. \& Abdo, M. A. 2016. Comparação entre a citopatologia por biopsia com agulha fina e a histopatologia no diagnóstico das neoplasias cutâneas e subcutâneas de cães. Pesquisa Veterinária Brasileira, 36, 197-203.

Braz, P. H., Sartoretto, M. C., Souza, A. S. \& Melo, F. M. G. 2015. Perfil hematológico de cães naturalmente infectados por Leishmania spp. Acta Veterinaria Brasilica, 9, 87-90.

FNS. 2010. - Fundação Nacional de Saúde. Ministério da Saúde.

Godoy, K. C. S., Antunes, T. R., Braz, P. H., de Assis, A. R., da Silveira, A. W. \& Souza, A. I. 2017. Comportamento dos marcadores bioquímicos de injúria hepática nos cães com leishmaniose visceral. Pubvet: Publicações em Medicina Veterinaria e Zootecnia, 11, 670-675.

Godoy, K. C. S., Braz, P. H., Assis, A. R., Antunes, T. R., Gomes, D. C. \& Souza, A. I. 2016. Avaliação dos indicadores de lesão miocárdica em cães com leishmaniose visceral. Arquivo Brasileiro de Medicina Veterinaria e Zootecnia, 68, 313-320.

Gontijo, B. \& Carvalho, M. d. L. R. 2003. Leishmaniose tegumentar americana. Revista da Sociedade Brasileira de Medicina Tropical, 36, 71-80.

Greene, C. E., Samperio, J. O. \& Gómez, J. P. 1993. Enfermedades infecciosas: Perros y gatos. Editora Interamericana, São Paulo.

Lima, M. A. M., Maia, J. S., Zanetti, K., Reginaldo, A. S. \& Braz, P. H. 2014. Comparação da sensibilidade do teste parasitológico em linfonodo, medula óssea e mucosa conjuntival para o diagnóstico de leishmaniose em cães. Acta Veterinaria Brasilica, 8, 274-276. 
Moreira, A. E. 2012. Aspectos hematológicos de pacientes com leishmaniose visceral. Academia de Ciência e Tecnologia, 1, 30-39.

Salzo, P. S. 2008. Aspectos dermatológicos da leishmaniose canina. Nosso Clínico, 11, 30-34.

Silva, A. A. L. 2007. Estudo clínico-laboratorial das articulações de cães naturalmente infectados com leishmaniose visceral e experimentalmente inoculados com Leishmania chagasi por via intra-articular. Faculdade de Odontologia. Universidade Estadual Paulista "Julio de Mesquita Filho" Faculdade de Odontologia -.
Teixeira, D. E., Benchimol, M., Rodrigues, J. C. F., Crepaldi, P. H., Pimenta, P. F. P. \& de Souza, W. 2013. The cell biology of Leishmania: how to teach using animations. PLOS Pathogens, 9, e1003594.

Article History:

Received 17 June, 2017

Accepted 24 July, 2017

Available online 1 September 2017

License information: This is an open-access article distributed under the terms of the Creative Commons Attribution License 4.0, which permits unrestricted use, distribution, and reproduction in any medium, provided the original work is properly cited. 